Yoanna Skrobik Ramona O. Hopkins

\section{Post-intensive care cognitive impairment: questions in mind?}

Received: 26 August 2012

Accepted: 27 August 2012

Published online: 18 January 2013

(C) Springer-Verlag Berlin Heidelberg and ESICM 2012

This editorial refers to the article available at: doi:10.1007/s00134-012-2784-9.

\author{
Y. Skrobik \\ Department of Critical Care Medicine, Maisoneuve-Rosemont \\ Hospital, Montreal, QC, Canada \\ R. O. Hopkins \\ Psychology Department and Neuroscience Center, \\ Brigham Young University, Provo, UT, USA \\ R. O. Hopkins \\ Department of Pulmonary and Critical Care Medicine, \\ Intermountain Medical Center, Murray, UT, USA \\ Y. Skrobik (四) \\ Lise and Jean Saine Critical Care chair Soins Intensifs, \\ Maisoneuve-Rosemont Hospital, 5415 Blvd. De l'Assomption, \\ Montreal, QC H1T 2M4, Canada \\ e-mail: yoanna.skrobik@umontreal.ca
}

\section{Introduction}

Each year millions of individuals are admitted and treated in intensive care units (ICUs) [1]. Better care has resulted in reduced mortality with a concomitant increase in ICU survivors, many of whom are left with significant morbidities. Large numbers of ICU survivors have cognitive impairments [2]; these impairments are new [3, 4], affect multiple cognitive domains, and are likely permanent. In this issue of Intensive Care Medicine, Wolters et al. [5] systematically review studies that assess cognitive impairment following critical illness. Quality was ascertained based on: (1) systematic baseline assessment of cognitive function (prospective or retrospective), (2) validated follow-up cognitive tests, (3) clear inclusion and exclusion criteria, and (4) adjustment for confounders such as age and gender. Studies had to evaluate patients more than 2 months after ICU discharge; cardiac surgery patients, case reports, reviews and data from animal studies were excluded. Cognitive impairment tests varied greatly, as did the rate of cognitive impairment, its definition, and time to follow-up ( 2 months to 13 years). The rate of cognitive impairment was $<10 \%$ in three of the five studies that used questionnaires or screening testbased cognition assessments; studies that used goldstandard neuropsychological tests found 45 to $80 \%$ of patients had moderate to severe cognitive impairment at follow-up. Loss to follow-up and study duration varied. In ten of the studies the mean age was 54 years or less at study enrollment. While this review highlights important findings regarding post-ICU cognitive impairment, questions remain regarding mechanisms, risk factors, patients' baseline cognitive function, recovery and effect of rehabilitation, and the relationship of cognitive impairments with quality of life and functional abilities.

\section{What we need to know to improve patient outcomes}

Mechanisms of cognitive impairment

The basic pathophysiology of cognitive impairment in survivors of critical illness is poorly understood. The heterogeneity of ICU populations and the lack of identified mechanisms of injury are challenging. In other populations, and probably in the critically ill, the mechanisms of cognitive impairment are complex, multifactorial, and likely interact with risk factors such as the number and type of comorbid disorders or genetic factors. ICU-related cognitive impairment is linked to hypoxemia [6], its duration [7], hypotension [8], glucose dysregulation 
[9, 10], and inflammation and cytokine activation [11]. The relative importance of these factors and their interplay are not identified. Whether cognitive sequelae can be modulated in ICU populations, particularly with regard to potentially reversible ICU complications, such as glucose control, has not been tested to date.

\section{Confounding variables}

Confounding variables associated with the development of cognitive impairments occur frequently in the critically ill. Age is among them. Many ICU patients are elderly; in Canada patients over 80 years constitute $16 \%$ of ICU admissions. The mean age was 54 years or less in ten of the studies reviewed by Wolters et al. [5]. Although the elderly were under-represented in this review (all studies enrolled older individuals), one study describes cognitive sequelae in 'older' (mean age 61) ICU survivors of 80 and $70 \%$ at 3 and 12 months, respectively [12]. Normal aging may be accompanied by cognitive decline or dementia [13]. Cognitive decline may occur as early as 45-49 years, with greater cognitive decline occurring in older individuals (ages 65-70 years) [14]. Wolters and colleagues [5] note that one important but unanswered question is whether the cognitive impairments are due to critical illness and their treatment or to the patients' poor premorbid health. Most cognitive outcome studies in critically ill populations have excluded patients with prior cognitive impairments or disorders associated with known cognitive impairments including cerebrovascular disease and dementia. Two large longitudinal population-based studies indicate that post-ICU cognitive impairment develops during or after the onset of critical illness [15, 16]. However, patients with hypertension, vascular disease, coronary disease, atrial fibrillation [17], and diabetes have high rates of cognitive impairment [18]; these patients may be over-represented among the critically ill, and as such the type and number of comorbid disorders may be risk factors for cognitive sequelae. For example, critically ill patients commonly develop multi-organ failure including renal failure; dialyzed patients over 55 purportedly have a $70 \%$ incidence of cognitive dysfunction $[19,20]$. In cardiovascular disease early investigations attributed cognitive decline to cardiac bypass surgery. However, cardiac populations with similar comorbidities and similarly rigorous cognitive testing without surgery have similar rates of cognitive decline as patients who have undergone surgery [21,22], suggesting that the use of rigorously selected control groups is important. The relationship between comorbid disorders and development of cognitive impairment in the critically ill has not been studied to date. In addition, surgery and anesthesia are associated with the development of cognitive impairments [23]. Postoperative cognitive dysfunction may affect a significant proportion of patients exposed to anesthesia, which may confound the cognitive outcome in surgical ICU patients. Whether anesthesia is associated with cognitive abnormalities in ICU survivors is unknown and remains to be investigated.

Baseline cognitive function, natural history of post-ICU cognitive impairment, and its risk factors

Few studies have addressed baseline cognitive function in ICU survivors and compared it to post-critical illness functioning in order to identify which patients recover to their pre-ICU level of function because of the unexpected nature of most critical illnesses. A small proportion ( 5-10\%) of ICU survivors are believed to have cognitive impairment prior to ICU admission, based on two large, population-based studies where cognitive function was tested at regular intervals $[15,16]$. Features by which risk can be stratified have not been identified. Intensive care unit delirium, a clinical feature associated with postICU cognitive impairment [12], may be preventable with measures such as early mobility or pharmacological prophylaxis. Whether depression or post-traumatic stress disorder, commonly described psychiatric morbidities in the critically ill, predict cognitive outcome as well as whether psychiatric symptoms [24] are risk factors for development of cognitive impairments [25] is also not clear.

\section{Recovery and rehabilitation}

Survivors of critical illness can have significant cognitive abnormalities at hospital discharge that improve over time. A recent study found variable cognitive outcome trajectories (impaired and stable, normal and stable, improvement, or decline), and further cognitive testing at hospital discharge did not predict 6-month cognitive outcomes in survivors of critical illness [26]. Given the inability to predict who will develop long-term cognitive impairment, treatments to prevent, ameliorate, or remedy cognitive impairments are needed. Limited data suggest that rehabilitation improves physical and cognitive function, but the rate of these changes is unclear, as is whether lifestyle patterns predict or influence its occurrence and speed [27]. Identifying which survivors of critical illness are likely to benefit from rehabilitation specifically targeted at post-ICU cognitive impairments [28] will require information as to mechanisms and risk factors as well as information regarding effectiveness of rehabilitation strategies. Cautious optimism is warranted as cognitive rehabilitation appears promising; a recent study describes a 6-week physical and cognitive rehabilitation protocol that led to better executive functioning than controls 
without rehabilitation [29]. We suspect that knowing which patients will benefit from these interventions, when to initiate them, which therapies are effective in ICU

populations, and how rehabilitation will be funded will all Conflicts of interest None. remain issues for clinical scientists for many years to come [28].

\section{References}

1. Adhikari NK, Fowler RA, Bhagwanjee S, Rubenfeld GD (2010) Critical care and the global burden of critical illness in adults. Lancet 376:1339-1346

2. Hopkins RO, Jackson JC (2009) Shortand long-term cognitive outcomes in intensive care unit survivors. Clin Chest Med 30:143-153 ix

3. Iwashyna TJ, Ely EW, Smith DM, Langa KM (2010) Long-term cognitive impairment and functional disability among survivors of severe sepsis. JamaJ Am Med Assoc 304:1787-1794

4. Ehlenbach WJ, Hough CL, Crane PK, Haneuse SJPA, Carson SS, Curtis JR, Larson EB (2010) Association between acute care and critical illness hospitalization and cognitive function in older adults. Jama-J Am Med Assoc 303:763-770

5. Wolters AE, Slooter AJ, van der Kooi AW, van Dijk D (2012) Cognitive impairment after intensive care unit admission: a systematic review. Intensive Care Med. doi: 10.1007/s00134-012-2784-9

6. Hopkins RO, Weaver LK, Collingridge D, Parkinson RB, Chan KJ, Orme JF Jr (2005) Two-year cognitive, emotional, and quality-of-life outcomes in acute respiratory distress syndrome. Am J Respir Crit Care Med 171:340-347

7. Mikkelsen ME, Christie JD, Lanken PN, Biester RC, Thompson BT, Bellamy SL, Localio AR, Demissie E, Hopkins RO, Angus DC (2012) The adult respiratory distress syndrome cognitive outcomes study: long-term neuropsychological function in survivors of acute lung injury. Am J Respir Crit Care Med 185:1307-1315

8. Hopkins RO, Weaver LK, Chan KJ, Orme JF Jr (2004) Quality of life, emotional, and cognitive function following acute respiratory distress syndrome. J Int Neuropsychol Soc 10:1005-1017

9. Hopkins RO, Suchyta MR, Snow GL, Jephson A, Weaver LK, Orme JF (2010) Blood glucose dysregulation and cognitive outcome in ARDS survivors. Brain Inj 24:1478-1484
10. Duning T, van den Heuvel I, Dickmann A, Volkert T, Wempe C, Reinholz J, Lohmann H, Freise H, Ellger B (2010) Hypoglycemia aggravates critical illness-induced neurocognitive dysfunction. Diabetes Care 33:639-644

11. Elenkov IJ, Iezzoni DG, Daly A, Harris AG, Chrousos GP (2005) Cytokine dysregulation, inflammation and wellbeing. NeuroImmunoModulation 12:255-269

12. Girard TD, Jackson JC, Pandharipande PP, Pun BT, Thompson JL, Shintani AK, Gordon SM, Canonico AE, Dittus RS, Bernard GR, Ely EW (2010) Delirium as a predictor of long-term cognitive impairment in survivors of critical illness. Crit Care Med 38:1513-1520

13. Plassman BL, Langa KM, Fisher GG, Heeringa SG, Weir DR, Ofstedal MB, Burke JR, Hurd MD, Potter GG, Rodgers WL, Steffens DC, McArdle JJ, Willis RJ, Wallace RB (2008) Prevalence of cognitive impairment without dementia in the United States. Ann Intern Med 148:427-434

14. Singh-Manoux A, Kivimaki M, Glymour MM, Elbaz A, Berr C, Ebmeier KP, Ferrie JE, Dugravot A (2012) Timing of onset of cognitive decline: results from Whitehall II prospective cohort study. BMJ 344:d7622

15. Ehlenbach WJ, Hough CL, Crane PK, Haneuse SJ, Carson SS, Curtis JR, Larson EB (2010) Association between acute care and critical illness hospitalization and cognitive function in older adults. JAMA 303:763-770

16. Iwashyna TJ, Ely EW, Smith DM, Langa KM (2010) Long-term cognitive impairment and functional disability among survivors of severe sepsis. JAMA 304:1787-1794

17. Marzona I, O’Donnell M, Teo K, Gao P, Anderson C, Bosch J, Yusuf S (2012) Increased risk of cognitive and functional decline in patients with atrial fibrillation: results of the ONTARGET and TRANSCEND studies. CMAJ 184:E329-E336
18. Richardson K, Stephan BC, Ince PG, Brayne C, Matthews FE, Esiri MM (2012) The neuropathology of vascular disease in the medical research council cognitive function and ageing study (MRC CFAS). Curr Alzheimer Res 9(6):687-696

19. Murray AM (2008) Cognitive impairment in the aging dialysis and chronic kidney disease populations: an occult burden. Adv chronic kidney Dis 15:123-132

20. Hocker J, Stapelfeldt C, Leiendecker J, Meybohm P, Hanss R, Scholz J, Bein B (2009) Postoperative neurocognitive dysfunction in elderly patients after xenon versus propofol anesthesia for major noncardiac surgery: a doubleblinded randomized controlled pilot study. Anesthesiology 110:1068-1076

21. van Dijk D, Moons KG, Keizer AM, Jansen EW, Hijman R, Diephuis JC, Borst C, de Jaegere PP, Grobbee DE, Kalkman CJ (2004) Association between early and three month cognitive outcome after off-pump and on-pump coronary bypass surgery. Heart 90:431-434

22. Selnes OA, Grega MA, Bailey MM, Pham LD, Zeger SL, Baumgartner WA, McKhann GM (2009) Do management strategies for coronary artery disease influence 6-year cognitive outcomes? Ann Thorac Surg 88:445-454

23. Terrando N, Brzezinski M, Degos V, Eriksson LI, Kramer JH, Leung JM, Miller BL, Seeley WW, Vacas S, Weiner MW, Yaffe K, Young WL, Xie Z, Maze M (2011) Perioperative cognitive decline in the aging population. Mayo Clin Proc 86:885-893

24. Okura T, Plassman BL, Steffens DC, Llewellyn DJ, Potter GG, Langa KM (2011) Neuropsychiatric symptoms and the risk of institutionalization and death: the aging, demographics, and memory study. J Am Geriatr Soc 59:473-481 
25. Hopkins RO, Key CW, Suchyta MR, Weaver LK, Orme JF Jr (2010) Risk factors for depression and anxiety in survivors of acute respiratory distress syndrome. Gen Hosp Psychiatry 32:147-155

26. Woon FL, Dunn CB, Hopkins RO (2012) Predicting cognitive sequelae in survivors of critical illness with cognitive screening tests. Am J Respir Crit Care Med 186(4):333-340

27. Norton MC, Dew J, Smith H, Fauth E, Piercy KW, Breitner JC, Tschanz J, Wengreen H, Welsh-Bohmer K (2012) Lifestyle behavior pattern is associated with different levels of risk for incident dementia and Alzheimer's disease: the Cache County study. J Am Geriatr Soc 60:405-412
28. Needham DM, Davidson J, Cohen H, Hopkins RO, Weinert C, Wunsch H, Zawistowski C, Bemis-Dougherty A, Berney SC, Bienvenu OJ, Brady SL, Brodsky MB, Denehy L, Elliott D, Flatley C, Harabin AL, Jones C, Louis D, Meltzer W, Muldoon SR, Palmer JB, Perme C, Robinson M, Schmidt DM, Scruth E, Spill GR, Storey CP, Render M, Votto J, Harvey MA (2012) Improving long-term outcomes after discharge from intensive care unit: report from a stakeholders' conference. Crit Care Med 40:502-509
29. Jackson JC, Ely EW, Morey MC, Anderson VM, Denne LB, Clune J, Siebert CS, Archer KR, Torres R, Janz D, Schiro E, Jones J, Shintani AK, Levine B, Pun BT, Thompson J, Brummel NE, Hoenig H (2012) Cognitive and physical rehabilitation of intensive care unit survivors: results of the RETURN randomized controlled pilot investigation. Crit Care Med 40:1088-1097 